\title{
La poesía de Miguel Sánchez, el Divino
}

\section{The Poetry of Miguel Sánchez, el Divino}

\author{
Víctor de Lama \\ Universidad Complutense de Madrid
}

\section{RESUMEN}

Sorprende la escasa atención de la filología hacia un poeta y dramaturgo como Miguel Sánchez que gozó de fama notable a finales del siglo XVI y principios del XVII. Autores como Rojas Villandrando, Cervantes y varios más le dedicaron sinceros elogios. Lope de Vega lo nombra varias veces con sentida admiración y en el Arte nuevo de hacer comedias le reconoce la invención de «engañar con la verdad» como recurso teatral. Tras la publicación de la monografía de Stefano Arata, empieza a ser reconocido como autor dramático en las historias del teatro del Siglo de Oro, pero hasta ahora nadie se había ocupado de reunir su poesía, editarla y estudiarla. En este trabajo se editan las escasas poesías conocidas del autor y se analizan por separado con el objeto de perfilar su original idiosincrasia y versatilidad como poeta. A la vez, algunos rasgos humorísticos de este corpus poético nos explican a las claras las razones de su éxito entre los contemporáneos y quizá los motivos íntimos de su silenciosa desaparición de la escena literaria en la primera década del siglo XVII.

Palabras Clave: Miguel Sánchez; Valladolid; poesía burlesca; literatura española del Siglo de Oro.

\begin{abstract}
The reduced critical attention paid by philologists to Miguel Sánchez, poet and playwright who enjoyed considerable fame in the years of change between the 16th and 17th century, is astonishing. Authors like Rojas Villandrando, Cervantes and several others have devoted sincere praise to Sánchez. Lope de Vega refers to him several times with heartfelt admiration and in the Arte nuevo de hacer comedias credits his theatrical invention of «deceiving with the truth». After Stefano Arata's monography, Miguel Sánchez begins to be recognized as a playwright in the theater of the Golden Age, but no one had cared to gather, edit and study his poetry. This paper provides a handful of verses allowing us to discover his original idiosyncrasy and versatility as a poet. Furthermore, some comical features of this poetic corpus give us clear reasons for the author's success among contemporaries and perhaps the inner motives of his silent disappearance of the literary scene in the first decade of the 17 th century.
\end{abstract}

Key words: Miguel Sánchez; Valladolid; Burlesque poetry; Spanish Golden Age literature. 


\section{Elogios DE SUS CONTEMPORÁNEOS}

Resulta paradójico que un escritor tan elogiado en su tiempo como Miguel Sánchez haya sido tan ignorado por la crítica. Como poeta dramático, en los últimos años empieza a ser conocido. Como poeta lírico, su obra y su significación han pasado desapercibidas: ninguna publicación se ha dedicado a recopilar su obra poética y ni un solo artículo se ha ocupado de estudiar su significación como poeta. Puede valer la pena, de entrada, conocer lo que decían de él sus contemporáneos antes de analizar su obra poética y valorar hasta qué punto esos elogios estaban bien fundados.

Coetáneo de Lope de Vega, Miguel Sánchez fue tan admirado por el Fénix que lo cita en su Arte nuevo de hacer comedias al hablar del lenguaje anfibológico reconociéndole una aportación fundamental en la gestación de la comedia nueva: el procedimiento de «engañar con la verdad»:

El engañar con la verdad es cosa que ha parecido bien, como lo usaba en todas sus comedias Miguel Sánchez, digno por la invención de esta memoria (vv. 319-322)1.

Al menos en tres ocasiones más, antes y después de componer el Arte nuevo (publicado en la edición de sus Rimas de 1609), el Fénix lo nombra con elogios. En La Arcadia (1598, pero es obra de larga gestación) lo incluye en un nutrido grupo de poetas, junto a Francisco de la Cueva y a Miguel Cejudo (Vega, 1975: 425). Luego en 1621 lo vuelve a elogiar en La Filomena por honrar a las Musas del monte Parnaso, en cuya ladera se encuentra la fuente Castalia ${ }^{2}$. Pero es en 1630, en el Laurel de Apolo, donde le dedica los versos más sentidos a modo de epitafio y le concede un mérito indiscutible como heredero del arte de Terencio ${ }^{3}$.

En los últimos años de su vida, un Cervantes poco amigo de Lope de Vega no duda en tributar palabras elogiosas en su Viaje del Parnaso (1614) a Mi-

\footnotetext{
${ }^{1}$ Lope menciona a muchos autores clásicos, pero aparte de Sánchez, sólo dos dramaturgos españoles merecen su recuerdo en el Arte nuevo: Lope de Rueda, que en sus comedias imitaba las «vulgares acciones y negocios» (v. 63) y el capitán Virués, porque «puso en tres actos la comedia, que antes / andaba en cuatro, como pies de niño» (vv. 216-217).

${ }^{2}$ «Y ya en España con la dulce lyra / resplandece en su fábrica Belmonte, / Don Lorenzo Vander honra a Granada. / y Miguel Sánchez el Castalio Monte» (Vega, 1621: ff. 155r-155v).

3 «El dulce cristalífero Pisuerga, / que como centro del sagrado Apolo / tantos ingenios délficos alberga, / a aquel en lo dramático tan solo, / que no ha tenido igual desde aquel punto / que el coturno dorado fue su asunto, / Miguel Sánchez, que ha sido / el primer maestro que han tenido / las Musas de Terencio, / propuso, aunque con trágico silencio. / Matóle el sol de la inclemente Vera, / porque le anticipó la primavera / y con la variedad de los colores / pensó que los concetos eran flores». Y un poco más adelante lo vuelve a recordar así: «El fénix que lloró Pisuerga tanto, / y que mató Plasencia, / en don Gabriel de Henao hoy resucita. / Venid musas, venid al dulce canto...» (Vega, 1630: ff. 28v-29 y 29v).
} 
guel Sánchez, junto a Miguel Cejudo. Destaca Cervantes su destreza poética, encareciendo «los pies de sus versos bien compuestos / llenos de erudición rara y dotrina» (Cervantes, 1995: 1250) las Ocho comedias lo elogia diciendo: «estímense las trazas artificiosas en todo estremo del licenciado Miguel Sánchez»(Cervantes, 1995: 26).

En 1603 Agustín de Rojas Villandrando lo había calificado de «divino» en la «Loa de la comedia» pieza contenida en El viaje entretenido:

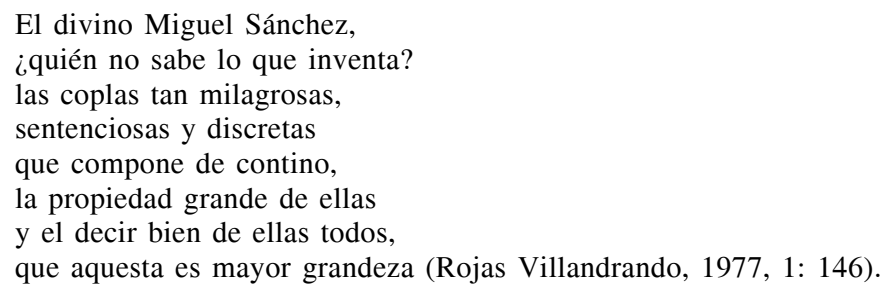

Conviene retener estas palabras de Agustín de Rojas, pues reúnen el juicio más completo y exacto sobre su condición de poeta. También con el calificativo «divino» es nombrado en 1615 por el editor Francisco de Ávila al frente de una de sus obras cuando escribe: «Comedia famosa de La Guarda Cuidadosa, compuesta por el divino Miguel Sánchez, vezino de la ciudad de Valladolid». Muchos más elogios se dirigieron a Miguel Sánchez en los años finales del siglo XVI y en el primer tercio del XVII. En 1594 lo nombra López Henríquez de Calatayud en su traducción de El nacimiento y primeras empresas del Conde Orlando en un plano de igualdad con Lope de Vega. Miguel Sánchez le había dedicado un soneto y el traductor se lo paga en el interior del libro con unos versos sobre la filiación terenciana de su teatro ${ }^{5}$. Poco después, Jiménez Patón en su Elocuencia española en arte (1604), hablando de la figura del «énfasis», lo nombra: «Y aunque esta es buena me parece boníssima la de Miguel Sánchez en el romance que dize: Melisendra está en Sansueña, / vos en París descuidado, / vos ausente, ella mujer: / harto os he dicho, ¡miraldo!» (Jiménez Patón, 1604: f. 81r).

Parece claro que los dramaturgos coetáneos conocían bien el arte de Miguel Sánchez, pero muy distinto es que su nombre fuera utilizado como referencia paradigmática entre el público de los corrales. Esto es exactamente lo que se desprende de unos versos de Guillén de Castro en La verdad averiguada, comedia fechada entre 1608 y 1612 (Bruerton, 1944: 131-133).

\footnotetext{
${ }^{4}$ Estas palabras son atribuidas igualmente a Miguel Cejudo, humanista y caballero de la Orden de Calatrava nacido en Valdepeñas.

${ }^{5}$ «La Academia de ingenios veo muy claros; / Lope de Vega veo en los primeros, cuyos versos al mundo son tan raros / que los de Plauto pueden ser postreros. / Y a Miguel Sánchez, que no son avaros / los cómicos coturnos tan severos, / que tiene de Terencio los conceptos / y aún sigue en todo trance sus efectos» (Alonso Cortés, 1926: 152).

${ }^{6}$ Estos son los versos: «Por los cielos / que aunque Miguel Sánchez fuera, / en sus comedias no hiciera / más bien un paso de celos» (Castro, 1925: 263b)
} 
De 1615, por tanto contemporánea de las menciones de Cervantes, es la de Suárez de Figueroa en su Plaza universal, que lo incluye en una larga lista de autores teatrales (Suárez de Figueroa, 1615: f. 323r). Mucho más expresiva es la admiración de Herrera Maldonado en su Sannazaro español (1620) ponderando su elocuencia7. Todavía en 1636 Fabio Franchi, seudónimo de Juan Antonio de Vera y Figueroa, que era embajador de España en Venecia, lo menciona póstumamente en sus Essequie poetiche dedicadas a Lope de Vega, como perteneciente a una generación ya pasada, oponiéndola a la de autores en boga (Pérez Montalbán, Vélez de Guevara o Calderón), lo cual nos indica que su recuerdo permanecía más vivo que el de otros muchos (Franchi, 1636; tomo la referencia de Arata, 1985: 127). Y aún al mediar el siglo el erudito Diego de Vich en su Discurso en favor de las comedias y de su representación (Valencia, 1650) lo sigue recordando junto al Fénix: "Y luego en mayores chapines Lope de Vega y Miguel Sánchez en Castilla, Gaspar de Aguilar y el Canónigo Tárrega en Valencia...».

Todas estas referencias nos hablan de una fama bien asentada en los últimos años del siglo XVI y el primer tercio del XVII. Luego el olvido de nuestro autor se perpetúa en las revisiones de nuestro teatro áureo y Miguel Sánchez es un dramaturgo ausente en la práctica totalidad de las historias del teatro español publicadas en los últimos cien años. Solo después del libro de Stefano Arata, Miguel Sánchez il «Divino» e la nascita della comedia nueva (1989), Ignacio Arellano le dedica una página en su Historia del teatro español del siglo XVII (1995), lo mismo que Héctor Urzáiz en la Historia del teatro español, dirigida por Javier Huerta (Huerta, 2003) ${ }^{8}$.

No es que Miguel Sánchez fuera totalmente desconocido por los estudiosos del teatro barroco, pues pueden rastrearse en el siglo XIX las menciones de Eugenio Ochoa y de Cayetano A. de la Barrera. Además, Hugo Rennert publicó tempranamente las dos obras que según su editor podían atribuírsele con fundamento: La isla bárbara y La guarda cuidadosa (1896). La edición de Rennert, publicada en Boston, apenas se distribuyó por España y no es fácil encontrar ejemplares de la misma en nuestras bibliotecas. Pero como Miguel Sánchez ya no era un dramaturgo estrictamente inédito, nadie se volvió a ocupar de editar su obra en el siglo XX. Ernest Merimée en su Précis d'histoire de la Littérature Espagnole (1908) es uno de los pocos que lo citan en

${ }^{7}$ «Quién bastará a cantar con voz humana / de Miguel Sánchez la eloquencia suma, / pues que vence su pluma soberana /de la fama inmortal la leve pluma» (Herrera Maldonado, 1620: f. 57).

${ }^{8} \mathrm{Mi}$ artículo reciente (Lama, 2011) ofrece alguna luz sobre una principal aportación de Miguel Sánchez a la comedia nueva, el procedimiento de engañar con la verdad, mérito que había sido prácticamente ignorado por la crítica en el siglo XX. En la misma línea de reivindicación de su figura se sitúa mi trabajo «Miguel Sánchez en el Arte nuevo y sus avatares editoriales» (Lama, 2013). 
los manuales de literatura española más tempranos ${ }^{9}$. Un par de artículos de Narciso Alonso Cortés, que revelaba la identidad inequívoca de nuestro dramaturgo, no tuvieron mucha difusión, así que hasta la mencionada monografía de Stefano Arata, Miguel Sánchez apenas era más que un nombre y un apellido, tan comunes, que se perdían y confundían en la abundante nómina de autores dramáticos de los Siglos de Oro.

\section{Noticia BIOGRÁfiCA DE Miguel SÁNCHEZ}

Entre las razones de su olvido hay que mencionar la ausencia de una biografía mínima que, por lo menos, respaldara la autoría de las escasas comedias y poesías conservadas a su nombre. Fue Narciso Alonso Cortés quien más contribuyó a esbozar la biografía de Miguel Sánchez en un par de artículos (Alonso Cortés, 1921: 123-131; y Alonso Cortés, 1944: 5-58). Luego Stefano Arata (1989) completó esa información con alguna noticia nueva. Recojo sumariamente estos datos.

Miguel Sánchez era natural de Valladolid y esto se sabía al menos por las menciones de Lope de Vega y de Francisco de Ávila. En el siglo XVIII el erudito Félix Latassa lo considera originario de Aragón sin fundamento sólido y lo incluye en su Biblioteca de escritores aragoneses. Bastante después Cayetano A. de la Barrera, en su célebre Catálogo bibliográfico y biográfico del teatro antiguo español (Madrid, 1860), afirma que era natural de Piedrahíta por haberlo confundido con un Juan Sánchez que era de esa localidad abulense. El error se ha perpetuado ${ }^{10}$ a pesar de que Alonso Cortés demostrara sin lugar a dudas que era vallisoletano, pues un documento de la Universidad de Valladolid fechado el 17 de diciembre de 1584 señala que «el dicho dotor Meneses dio el grado de Bachiller [en Cánones] a Miguel Sánchez, natural de esta villa de Valladolid» (Alonso Cortés, 1921: 127) ${ }^{11}$. De esta fecha se puede deducir que nació entre 1563 y 1566, pues el título de bachiller

${ }^{9}$ Por ser escasas las menciones, vale la pena traer aquí las palabras del historiador francés: «Le qualificatif de Divino (bien prodigué, il est vrai!) et les hiperboliques éloges des contemporaines nous font regretter de ne posséder qu'une faible partie de l'œuvre du D. Miguel Sánchez, de Piedraita de Pisuerga. Son romance de Gaiferos (cité dans le Quijote), les Silvas del Inocente Cordero (1605), et deux pièces: la Guarda cuidadosa et La isla bárbara, ne peuvent nous donner qu'une idée incomplète de ce poète, qui écrivait déjà dans la dernière décade du XVIe siècle» (1908: 309).

${ }^{10}$ Veíamos el dato curioso de Mérimée («Piedrahíta de Pisuerga»), fruto de un cruce de informaciones. I. Pepe Sarno y J.M. ${ }^{a}$ Reyes Cano (Espinosa, 2006: 30) siguen considerándolo de Piedrahíta, pero luego, en evidente contradicción, afirman que era «posiblemente vallisoletano» (2006: 719).

${ }^{11}$ Aunque siempre la homonimia puede jugarnos malas pasadas, no parece que sea el caso, pues hay otros datos concomitantes que apoyan la convicción de que se refiere al dramaturgo. 
se conseguía generalmente entre los 18 y los 21 años. Su nombre completo era Miguel Sánchez Requejo ${ }^{12}$ y por un testimonio de 1592 sabemos que entonces ya era Licenciado ${ }^{13}$.

Entre los años 1596 y 1600 entró al servicio del primer obispo que tuvo Valladolid, Bartolomé de la Plaza, en unos momentos en que la ciudad fue víctima de un brote de peste negra que en 1599 asoló Castilla y a consecuencia de la cual falleció este prelado ${ }^{14}$. Es probable que poco después de 1603 Miguel Sánchez fuera nombrado secretario de Enrique Enríquez, cuando Felipe III lo presentó para el obispado de Osma, de donde tomó posesión en 1605. Se trataba de un cargo importante, pues Enrique Enríquez ya era Provincial de los conventos agustinos de Castilla y pertenecía a una de las más influyentes familias vallisoletanas ${ }^{15}$. Con todo, este nombramiento suponía alejarse de la nueva Corte del reino en un momento de intensa actividad cultural. Stefano Arata dio a conocer una carta interesantísima, fechada en Valladolid el 13 de diciembre de 1606, en la que Miguel Sánchez ejerce de crítico literario a instancias nada menos que de don Diego Sarmiento de Acuña, el célebre Conde de Gondomar ${ }^{16}$, lo cual indica que nuestro autor pudo pasar alguna temporada en Valladolid. Parece erróneo el dato según el cual Miguel Sánchez fue secretario del obispo de Cuenca ${ }^{17}$.

En 1610 Enrique Enríquez es destinado a Plasencia, ciudad en la que residió como obispo hasta su muerte en 1622. Carecíamos hasta ahora de datos concretos sobre la vida de nuestro autor en esta segunda década del siglo. Con-

${ }^{12}$ Con estos apellidos aparece el autor de un soneto encomiástico en un libro publicado en Valladolid en 1594 y también como Miguel Sánchez Requejo es nombrado en un documento de 1605 como secretario del obispo de Osma.

${ }^{13}$ En el libro de Francisco de Montanos, Arte de música theórica y práctica (1592), se imprime un soneto laudatorio «del Licenciado Miguel Sánchez, el autor».

${ }^{14}$ Alonso Cortés (1921: 127-128) aduce un documento, fechado el 11 de agosto de 1603, por el cual el Ayuntamiento certifica los buenos servicios prestados por Miguel Sánchez durante la peste siendo secretario del obispo Bartolomé de la Plaza.

${ }^{15}$ Era hijo de Martín Enríquez, Virrey del Perú, y de doña María Manrique. El 29 de mayo de 1605 en Valladolid asistió al cardenal de Toledo en el bautismo de Felipe IV, juntamente con el arzobispo de Burgos y los obispos de Valladolid, Segovia y Astorga.

${ }^{16}$ Don Diego Sarmiento fue Corregidor de Valladolid cuando era capital del reino y luego muy elogiado como embajador en Londres; este bibliófilo atesoraría en su palacio vallisoletano, la Casa del Sol, la más rica biblioteca privada de toda Castilla en su tiempo. De la carta mencionada se desprende que el conde había encargado una comedia genealógica, Los Sarmientos, sobre un antepasado ilustre y deseaba la opinión autorizada del Divino poco después de ser representada. Stefano Arata (1996: 18-19) copia dicha carta, que se conserva en la Real Academia de la Historia (sign. 9/79).

${ }^{17}$ En un discurso a favor de la comedia de Antonio Navarro se afirma que Miguel Sánchez fue secretario del obispo de Cuenca. Arata (1989: 21) demuestra que Enrique Enríquez fue propuesto en 1609 para ocupar el obispado de esa ciudad, pero no llegó a tomar posesión porque su ocupante, el anciano Andrés Pacheco, que debía trasladarse a Sevilla declinó la oferta y se quedó en Cuenca. 
servamos varios elogios de esta época, Francisco de Ávila incluye su comedia La guarda cuidadosa en la Quinta parte de Flor de las comedias de España de diferentes autores (Alcalá de Henares, 1615) y por esos años se representa en Murcia y en Lisboa La isla bárbara. En fin, por el epitafio de Lope de Vega en el Laurel de Apolo, sabemos que Miguel Sánchez murió en Plasencia, pero se desconoce si falleció antes o después que el prelado al que servía.

La actividad de Miguel Sánchez se desarrolló en el Valladolid de las últimas décadas del siglo XVI, una ciudad culta en la que se había establecido la Corte entre 1540 y 1561 , y que se distinguía por los abundantes abogados, profesores y médicos que ejercían en torno a dos instituciones de primer orden: la Real Chancillería, tribunal principal de toda Castilla, y la Universidad. Esto sin contar el colectivo de los religiosos y los militares de alto grado que, en torno a una imprenta bien desarrollada, podían aspirar a publicar sus creaciones ${ }^{18}$.

\section{Miguel SÁnchez, POETA}

La crítica tradicional ha atribuido a Miguel Sánchez solo dos poesías que se imprimieron en los años cercanos al cambio del siglo XVI al XVII: el romance caballeresco Oíd, Señor don Gaiferos y la Canción a Cristo crucifica$d o^{19}$. Con estos dos únicos poemas, tan diferentes en su inspiración, resultaba difícil delinear el perfil literario de un autor en un momento en que se estaba produciendo una seria transformación de la poesía renacentista.

En sus pesquisas biográficas sobre nuestro autor, Alonso Cortés descubrió tres sonetos encomiásticos. Alude a ellos también Stefano Arata en la monografía sobre nuestro autor, pero luego nadie se ha ocupado de reunir sus versos y de analizarlos. Parece claro que, como sucedió con sus comedias, la mayor parte de la producción poética de Miguel Sánchez se ha perdido. Por eso creo que es necesario traer aquí estos poemas suyos olvidados, y algún otro desconocido, para reunir su obra poética dispersa. Podremos luego estudiarlos y valorar así sus posibles méritos literarios, teniendo a la vista las palabras elogiosas que le dedicaron sus contemporáneos. Empezaremos por referir la tradición textual de esos dos poemas conocidos.

\section{«Oíd, señor don Gaiferos» [1593]}

El romance que así empieza apareció impreso a nombre de Miguel Sánchez en el Quinto quaderno de la segunda parte de varios romances (Valencia: Juan

\footnotetext{
${ }^{18}$ Un panorama muy completo sobre la ciudad nos lo ofrece Bartolomé Bennassar (1989). Para conocer la vida literaria por aquellos años debe consultarse el libro de N. Alonso Cortés Noticias de una corte literaria (1906) y su artículo «Los poetas vallisoletanos celebrados por Lope en el Laurel de Apolo» (1944).
} 
del Molino de la Rovella, 1593), luego figura anónimo en el Romancero general (Madrid: Luis Sánchez, 1600) (Huntington, 1904) y es uno de tantos que se compusieron sobre el romance viejo de Gaiferos y Melisendra. Las aventuras de estos peculiares amantes fueron narradas en varios romances carolingios y se hicieron muy populares. En el Cancionero de romances ( $\sin$ año, pero h. 1550) se recoge un Romance de don Gaiferos que trata de cómo sacó a su esposa, que estaba en tierra de moros... que Cervantes recrea burlescamente en el cap. XXVI, II del Quijote $^{20}$. Fue glosado en muchos entremeses del siglo XVII, como señala Eugenio Asensio en su Itinerario del entremés, y en varias comedias mencionadas por Daniel Devoto, entre ellas alguna de Lope y de Tirso (Asensio, 1965: 70-71; Devoto, 1989: 181). En fin, del romance de Gaiferos y Melisendra circularon varias versiones paródicas entre las que destaca la de Góngora «Desde Sansueña a París» (Góngora, 1982: nº XXV).

Podemos estar seguros de que Cervantes la conocía bien, pues en el capítulo mencionado del Quijote cita el v. 12 «Harto os he dicho, miraldo» en un contexto tan jocoso que seguramente se hizo proverbial. Ya indiqué más arriba que Jiménez Patón utilizó cuatro versos del romance de Sánchez para ejemplificar la figura del «énfasis». Salas Barbadillo en sus epigramas también se hace eco del verso «Harto os he dicho, miradlo» ${ }^{21}$ y Gonzalo Correas cita este verso como frase proverbial en su Vocabulario...22.

${ }^{19}$ Estos son los únicos que menciona Rennert en la introducción a la edición de sus obras. Todavía en 1980 Vern G. Williamsen (1980: 803) le sigue atribuyendo sólo esas dos composiciones poéticas. Ambas fueron muy elogiadas en el pasado. Ya a mediados del siglo XVIII un erudito como Mayans y Siscar atribuyó caprichosamente la Canción a Cristo Crucificado a Fray Luis de León, por considerarla más propia de su genio que de un Miguel Sánchez que él desconocía. El error de Mayans llevaba implícita la alta valoración de la canción. La misma admiración confiesa Cayetano A. de la Barrera cuando un siglo después, en su célebre Catálogo bibliográfico y biográfico del teatro antiguo español (1860), declara que «de sus composiciones líricas sólo poseemos dos, que por cierto son, cada una en su género, de lo más bello que atesora nuestro Parnaso».

${ }^{20}$ Los estudios sobre la leyenda de Gaiferos, emparentada con el héroe épico germánico Walter de Aquitania, son muy numerosos debido sobre todo a que Menéndez Pidal apoyaba en esta recreación romancística su tesis sobre el origen germánico de la épica castellana. Una monografía bastante completa sobre Gaiferos y sus orígenes germánicos, con una rica bibliografía, es la de Víctor Millet (1998), Épica germánica y tradiciones épicas hispánicas. Waltharius y Gaiferos. La leyenda de Walther de Aquitania y su relación con el romance de Gaiferos.

${ }^{21}$ Editó sus epigramas Emile Arnaud (1981: 30-86). El verso de Miguel Sánchez está en el epigrama 50: «Celia, a vuestro esposo Arnaldo / su fin aún no le llegó; / ya sabéis que hoy merendó, / harto os he dicho, miradlo» (1981: 39).

${ }^{22}$ Luego en pleno Romanticismo, junto con otros romances caballerescos anónimos sobre don Gaiferos, Eugenio de Ochoa publicó este romance atribuyéndoselo a Miguel Sánchez en su Tesoro de los romanceros y cancioneros históricos, caballerescos, moriscos y otros (1838). Son significativas las palabras de Ochoa en nota a la pieza de Miguel Sánchez: «Autor dramático de los más famosos del siglo XVII, de quien no nos queda otra comedia que la de La guarda cuidadosa». 


\section{«Canción a Cristo crucificado» [1605]}

Publicó esta canción Pedro Espinosa en su Primera parte de las flores de poetas ilustres (Valladolid: Luis Sánchez, 1605) (2006). La suerte de esta poesía ha sido más azarosa, pues en varias ocasiones se le ha atribuido a otro autor ${ }^{23}$. Debió de gustar en la época romántica pues la recogió, como anónima, Juan Nicolás Böhl de Faber en su Floresta de rimas antiguas castellanas (Hamburgo, 1821) ${ }^{24}$. Llama la atención que se haya seguido tantas veces la opinión de Mayans atribuyéndosela a Fray Luis de León, falta de todo fundamento textual, y que se haya despreciado la atribución de su primer antólogo Pedro Espinosa, poeta que debió de conocer personalmente a Miguel Sánchez en Valladolid cuando esta ciudad era la capital de España y el lugar donde se imprimió la célebre antología de Espinosa.

Miguel Sánchez se inscribe en la tradición religiosa que tan altos frutos dio desde los primeros tiempos de la Contrarreforma. Las oraciones a Cristo, desde la célebre de Francisco de Aldana, adoptan todas las formas métricas del momento, desde el soneto hasta la canción, pasando por los tercetos, las octavas, etc. Las estancias utilizadas por Miguel Sánchez combinando heptasílabos y en-

\footnotetext{
${ }^{23}$ Aparece atribuida a Lupercio Leonardo de Argensola en el ms. 56 (ff. 202-204v) del Monasterio de Montserrat (Olivar, 1977: 105-108) y ya hemos dicho que Gregorio Mayans en el siglo XVIII se la atribuyó por razones de estilo a Fray Luis de León en la edición de sus obras (Valencia, 1761), a pesar de haber utilizado para su edición la preparada por Quevedo de 1631 y la de Milán del mismo año, que no la incluyen. Aunque López de Sedano después, en el tomo V de su Parnaso español (1771), la restituyó a su autor, el colector de los Poesías espirituales de varios autores (Madrid, 1779) se la volvió a regalar a Fray Luis de León y figura impresa a nombre del fraile agustino en numerosas ocasiones. Luego la publicó, a nombre de Miguel Sánchez, Agustín Luis Josse (1802). Los problemas de autoría han continuado hasta la actualidad. Aparece en el tomo IV de la Obras del M. Fr. Luis de León, edición preparada por el P.M. Fr. Antolín Merino (1816), pp. 76-80, pues aunque Antolín Merino no la considera de Fray Luis, incluye la canción en el Apéndice Primero a la primera parte, con la observación en nota de que «esta obra no se halla en nuestros MSS. El P. Mtro. Ayala y el Maestro Mayans se la concede a nuestro autor [Fray Luis] y con su nombre se ha impreso varias veces. Pedro Espinosa la imprimió a nombre de Miguel Sánchez. No hallamos en ella el carácter poético del Mtro. León» (1816: 76). Un ejemplo de error reciente en su atribución es el que encontramos en el artículo de Carlos Mata Induráin (2008), «Literatura del ciclo de la Pasión: prosa y poesía» ([en línea], en www.unav.es/catedrapatrimonio/paginasinternas/recorriendopatrimonio/losarcos/literatura/ textospasion.pdf [ref. de 25/02/2015]). El error ahora se multiplica en internet ya que la canción puede encontrarse en diversas páginas a nombre de Fray Luis de León. José Manuel Blecua (1984: 13-30) examina ésta y otras atribuciones problemáticas en su trabajo «La transmisión de la obra poética de Fray Luis de León».

${ }^{24}$ Junto a los méritos reconocidos por Mayans y La Barrera, son muy elocuentes las palabras de López de Sedano en su Parnaso español: «Es la cosa más excelente que en su línea se ha escrito en nuestra lengua, pues no se la encuentra semejante en la delicadez (sic), ternura, suavidad y belleza de los pensamientos que forman uno de aquellos felices partos, que salen raras veces perfectos y robustos de la fecunda imaginación de un poeta» (López de Sedano, 1771: Índice, xviii).
} 
decasílabos le permiten una gran flexibilidad para modular sus sentimientos. La imagen humana de Cristo parece ser la que mejor se aviene con los intereses de los poetas del momento y para ello nada mejor que postular, en la primera estancia, una imagen dinámica del Redentor en la que aparezca volviéndose a mirar al poeta (vv.1-13). Nada extraño sería que Lope de Vega, uno de los más fervientes admiradores de Miguel Sánchez, tuviera in mente estos versos para ofrecernos una imagen de Cristo en movimiento en sus Soliloquios amorosos de un alma con Dios (1621), incluyendo la imagen de unos brazos abiertos que incitan al abrazo: «No miréis mis desconciertos, / que ya no podéis negarme / que queréis los brazos darme, / pues que los tenéis abiertos, / abracémonos, mi Dios...» («Soliloquio II») (Amselem-Szende, 2003: 31-32) ${ }^{25}$.

\section{OtRas POESÍAs OlVidadas de Miguel SÁNCHEZ}

En sus investigaciones sobre «los poetas del Pisuerga», Narciso Alonso Cortés dio a conocer tres sonetos encomiásticos de Miguel Sánchez que no han sido tenidos en cuenta por la crítica al tratar de la obra de nuestro autor. Lo mismo cabe decir del romance sobre la vida de San Roque, que Stefano Arata cita sin ninguna convicción sobre la paternidad de Miguel Sánchez.

\section{«De nuevo tiendes, Escobar, las velas» [1587]}

El soneto que así empieza figura en los preliminares del libro Luzero de la Tierra Sancta y grandezas de Egypto y monte Sinay, agora nuevamente

\footnotetext{
${ }^{25}$ La novedad de este planteamiento de Miguel Sánchez pudo alcanzar también a ciertas representaciones pictóricas del Crucificado. Hoy no cabe dudar de que los pintores pudieron y debieron inspirarse en la poesía religiosa de la época para diseñar la composición de los cuadros que les encargaban. Basta observar la analogía entre algunas pinturas de Francisco Ribalta (1565-1628) para los capuchinos de Valencia y la poesía mística de aquellos años. Es la tesis apuntada por D.F. Darby en su estudio Francisco Ribalta and his school (1938). Un ejemplo puede ser el Abrazo de San Francisco al Crucificado pintado por Ribalta hacia 1620 y que se custodia en el Museo de Bellas Artes de Valencia. En él nos presenta a Jesús en la cruz con la mano derecha desenclavada poniendo su corona de espinas a San Francisco, quien a su vez está abrazando por la cintura el cuerpo de Cristo. El hecho de que no se hayan encontrado antecedentes pictóricos para esta composición puede reforzar la tesis de la fuente literaria, habida cuenta de la simpatía de Lope de Vega por Miguel Sánchez y la amistad del Fénix con Francisco Ribalta. La estancia del pintor en Valencia entre 1599 y 1617 se ha explicado por su amistad con Lope de Vega. Asimismo se sabe que Ribalta realizó un retrato del Fénix, aludido por éste y hoy perdido, del que procede el grabado que se publicó como portada en las Rimas humanas y divinas del Licenciado Tomé de Burguillos en 1634. Bastante posterior, de 1668, es el cuadro de Murillo San Francisco abrazando al crucificado, del Museo de Bellas Artes de Sevilla, que seguramente se inspiró en el de Ribalta. Menos semejanza, aunque sí algún parentesco, ofrece el cuadro de Ribalta Cristo abrazando a San Bernardo, que también pudo basarse en la biografía de San Bernardo que Pedro Ribadeneyra recogió en su Flos sanctorum publicada en 1599.
} 
vistas y escriptas por Pedro de Escobar Cabeza de Vaca de la Orden de los Cavalleros Templarios de la Sancta Cruz de Hierusalem (1587), un poema en endecasílabos sueltos que tiene por objeto relatar su peregrinación a Tierra Santa una vez jubilado. La obra contó con una segunda edición (Valladolid: Diego Fernández de Córdova y Oviedo, 1594) acorde con el éxito que tenían entonces estos libros de peregrinación. Para interpretar cabalmente el poema, nos ayudará algo saber quién era su destinatario. Por el contenido de la obra, sabemos que Pedro de Escobar Cabeza de Vaca fue armado como Caballero Templario de la Santa Cruz de Jerusalén durante su estancia en la Ciudad Santa. Y por su libro sabemos que realizó un larguísimo periplo por los lugares santos de Palestina, Damasco y Egipto, incluido el monte Sinaí, acompañado por un sirviente turco. Cuando emprendió el viaje, era ya militar retirado y fueron sin duda sus fuertes convicciones religiosas las que le animaron a realizar el sueño de peregrinar a Tierra Santa. Afortunadamente se conservan dos testamentos sucesivos suyos en el Archivo Histórico de Protocolos de Valladolid ${ }^{26}$ (Rojo Vega, 2013) y por ellos sabemos que se casó con Ana Acero, probablemente a la vuelta de su peregrinación, que tuvieron un hijo, Marcos de Escobar, y que falleció en 1592, pocos meses después que su es$\operatorname{posa}^{27}$.

En este soneto encomiástico Sánchez cumple con los requerimientos del género, a fin de cuentas una forma especial de poesía de circunstancias: alu-

${ }^{26}$ Rojo Vega, Atanasio (ed.) (2013). «1592 Testamento e inventario de Pedro Escobar Cabeza de Vaca, autor del Luzero de Tierra Santa» [en línea]. http://www.anastasiorojo.com/ \#!/1592-testamento-e-inventario-de-pedro-escobar-cabeza-de-vaca-autor-del-luzero-de-tierrasanta [ref. de 25/02/2015].

${ }^{27}$ Hizo un primer testamento en Valladolid el 11 de agosto de 1591 (Archivo Histórico Provincial De Valadolid, AHPV, protocolos, leg. 421, fo. 1.412), con codicilos los días 11 y 12 de diciembre (AHPV, leg. 421, fo. 1.681 y 1.682) y redactó uno nuevo el 29 de enero de 1592 (AHPV, protocolos, leg. 759, s.f., con codicilo el 26 de Abril: AHPV, protocolos, leg. 759, s.f.). El 26 de mayo de ese año, tras su muerte en fecha no concretada, se hace inventario de sus bienes (unos pocos libros, entre ellos un Orlando enamorado y un Luzero de la Tierra Sancta) y deja setecientos reales durante diez años a los «Descalzos Carmelitas», que se habían de pagar la mitad por San Juan y la otra mitad por Navidad, y trescientos reales a las «Descalças Franciscas» de igual manera. Como tutor de su hijo legítimo, Marcos de Escobar, y de su mujer, nombra a Bautista de Vallejo, criado del duque de Nájera. En el primer testamento se afirma que Pedro Escobar era natural de la villa de Villacarralón (Valladolid) y por los bienes que deja deducimos que no era un alto aristócrata. Sin embargo, vemos que consigue publicar un libro relatando su peregrinación, dona unas considerables sumas a dos órdenes religiosas, deja suficientes bienes a su hijo y además encarga una capilla donde sería enterrado. Todo ello deja entrever que era un hidalgo de mediana fortuna, bien relacionado en Valladolid y digno de un soneto que recuerda no sólo su viaje, sino también sus servicios al rey y a la patria, junto con el alto concepto que Miguel Sánchez, seguramente amigo suyo, tenía de él. Está en prensa un artículo de Lama de la Cruz titulado «El vallisoletano Pedro Escobar Cabeza de Vaca en su Luzero de la Tierra Sancta» en el que se detallan interesantes aspectos de la personalidad del autor a través del estudio de su obra. 
sión al motivo que lo inspira, descripción del pasado del autor, elogio final... Pero además estos versos demuestran que Miguel Sánchez, ya en 1587, domina con soltura la composición del soneto, su estructura bipartita, el ajuste entre métrica y sintaxis y un final sorprendente. Manifiesta, por otro lado, destreza en el juego de palabras (velas /desvelas) concibiendo la publicación del libro como una nueva forma de «tender las velas» y «volar con heroica pluma» o, lo que es lo mismo, probar fortuna en la república de las letras. También es notable el juego de prestidigitación que realiza con palabras de la familia «medir» en los últimos cinco versos.

\section{«Cualquiera pecho en voz subida o grave» [1592]}

El destinatario de este soneto es Francisco de Montanos, el autor del Arte de música theórica y práctica $(1592)^{28}$. Francisco de Montanos era «Racionero de la Iglesia mayor» (la catedral) de Valladolid, fue reconocido en su tiempo como excelente músico y compaginaba su especialidad con su afición de poeta. Su Arte de música theórica y práctica, libro muy técnico, es importante en la historia de la teoría musical, pues conoció varias ediciones en los siglos XVII y XVIII ${ }^{29}$.

El soneto busca su originalidad en un cierto conceptismo y en juegos de palabras, a los que Miguel Sánchez era aficionado, como había demostrado en el soneto dedicado a Escobar. El poeta equipara la música de Montanos con la de los ángeles y en el último terceto, siguiendo su argumento, pide que sea Dios quien alabe al músico y haga eterna su memoria. El acusado hipérbaton se conjuga con un ritmo entrecortado por algunas pausas en el interior del verso, todo lo cual proporciona al poema un tono grave y armonioso, especialmente conseguido en el último terceto.

\section{«Muestra, Valladolid, nuevo contento» [1594]}

Otro soneto atribuido a Miguel Sánchez se lee en los preliminares de $E l$ Nascimiento y primeras empresas del conde Orlando, traduzidas por Pero López Henríquez de Calatayud, Regidor de Valladolid, dirigidas al Príncipe Don Philipe nuestro señor tercero deste nombre (Valladolid: Diego Fernández de Córdova y Oviedo, 1594). Este libro es la traducción al español del

\footnotetext{
${ }^{28}$ La obra, dedicada a Fernando de Castro Conde Lemos, está dividida en seis tratados: canto llano, canto de órgano, contrapunto, compostura, proporción y lugares comunes. El soneto «Del Licenciado Miguel Sánchez», seguido de otro del Licenciado Neyra, figura en la parte final del libro, en la sección del «Canto de órgano». En otras secciones encontramos poemas de Lomas Cantoral, Juan Ortiz, Francisco de la Cueva, Pedro Salgado y Antonio Quiñones. «El Privilegio» y la «Aprobación» están fechados respectivamente en junio y julio de 1587, lo cual no implica necesariamente que los sonetos estuvieran compuestos ya en ese año.

${ }^{29}$ Hace acopio de unos datos biográficos Pedro Aizpurua en «El vallisoletano Francisco de Montanos (s. XVI), teórico musical y polifonista» (1983).
} 
poema escrito en italiano por el veneciano Ludovico Dolce. El soneto de «Miguel Sánchez Requejo», («Muestra, Valladolid, nuevo contento»), como los otros cinco de otros tantos vates vallisoletanos, es un poema encomiástico, con versos bastante jocosos, dedicado al traductor de la obra, Henríquez de Calatayud ${ }^{30}$. Resulta muy ilustrativo que los elogios de nuestro poeta sean devueltos por el Regidor de Valladolid en su propio libro. En efecto, López Henríquez añade a su traducción un canto en el que alaba a los grandes autores del momento: a Gabriel Lasso de la Vega, a Juan de la Cueva y, junto a Lope de Vega, a Miguel Sánchez en los versos citados en la nota 5. La referencia es muy importante por ser temprana. Estamos en 1594 y vemos ya el nombre de Miguel Sánchez junto al de Lope de Vega, a la vez que se reconoce la vinculación del vallisoletano al arte de Terencio. Recordemos que mucho después, en 1630, el Fénix mencionaría el mismo motivo en el Laurel de Apolo: «Miguel Sánchez, que ha sido / el primer maestro que han tenido / las Musas de Terencio».

\section{«Romance de la vida de San Roque» [h. 1601-1605]}

En el ms. 3.795 (f. 74v) de la BNE (en adelante, ms. A), llamado a veces «manuscrito de Góngora» por la abundante presencia de poemas del cordobés, se encuentra un poema con la siguiente rúbrica: «Romance con que se cumple con un certamen que pedía se dijesse la vida de $\mathrm{S}$. Roque en breves palabras. Miguel Sánchez». Stefano Arata menciona este romance, pero no está convencido de la paternidad de Miguel Sánchez. Sin embargo, un análisis detenido del manuscrito revela que tanto la rúbrica del poema como el nombre de Miguel Sánchez y el texto han sido copiados por la misma mano ${ }^{31}$. Además, como se verá, la invención y trazas del poema delatan una concepción burlesca que se aviene perfectamente con las declaraciones de Rojas Villandrando y del propio Cervantes sobre Sánchez. El argumento es muy original: En primera persona, el personaje que desea participar en un peculiar certamen poético relata cómo se despierta y se viste apresuradamente, enciende la lumbre, abre las ventanas y manda buscar un libro (no picaresco, ni pastoril, ni de caballerías), un Flos sanctorum donde documentarse sobre

${ }^{30}$ Alonso Cortés (1926) demostró que este Regidor de Valladolid era una de las más eminentes personalidades de la ciudad. Aficionado a la poesía, alternaba sus tareas administrativas con las literarias y la traducción de este prolijo poema italiano sobre el célebre Orlando fue una principal ocupación para él. Por los autores que se prestaron a componer los sonetos de los preliminares, deducimos que estaba introducido en las tertulias de los médicos, juristas y académicos de la ciudad.

${ }^{31}$ Las dudas se deben a que Arata (1989: 26) considera que su nombre hubiera podido ser escrito por otra mano: «In testa al componimento, di mano seicentesca, si legge "Miguel Sánchez, en Valladolid estando la corte"». En realidad, el nombre del poeta está escrito por la misma mano que el texto; sólo la precisión, «en Valladolid estando la corte», es la que figura al margen del texto con letra diferente. 
la vida de san Roque. Siete escasos octosílabos dedica a la vida del santo y, ya con el papel firmado, le manda a su escudero llevar el papel a la iglesia de Santiago, donde tiene casa el cura al que debe decirle «que si es servidor de damas / que le defienda y que quándo / que vais por el premio manda». Los dos versos siguientes y finales culminan la burla: «Mirad que ay clérigos necios / no le digáis nuestra casa». Ese «yo poético» se considera acreedor del premio, no ya por la concisa vida del santo que presenta, sino porque si el cura «es servidor de damas», podrá tener también él su recompensa y todo ello sin revelar al cura quién le envía el romance o, al menos, dónde vive.

La justa poética en honor de San Roque, si es que existió, se celebró en lugar y fecha que hoy no podemos precisar ${ }^{32}$. Si no miente la glosa marginal, que lo sitúa «en Valladolid estando la corte», debemos datar esta composición entre 1601 y 1605, año este último en que Miguel Sánchez sale para Osma acompañando al obispo Enrique Enríquez. Ahora bien, el desenlace del mismo parece indicar que este romance no se llegó a presentar al certamen, pues tiene la apariencia de ser un poema de burlas, un divertido juguete con cualidades teatrales, que en los últimos versos satirizan al cura de la iglesia de Santiago, reclaman el premio del certamen, a la vez que el autor se protege en el anonimato. El romance presenta una sintaxis entrecortada, consecuencia del ritmo frenético que se imprime a la acción del protagonista, porque teme no llegar a tiempo para presentar su poema al certamen. Muchos octosílabos tienen dos partes: una pregunta y su respuesta o una admiración y una frase nominal. Tantas pausas, exclamaciones y preguntas configuran la andadura coloquial de este romance. Por su malicioso contenido y por su forma, no es casualidad que el texto se haya conservado únicamente manuscrito. Hasta aquí nada nos hace dudar de que estamos ante un original poema burlesco de Miguel Sánchez.

La cuestión, sin embargo, se complica al comprobar que tres testimonios más, todos ellos manuscritos, conservan este mismo romance, sin nombre de autor y con variantes significativas ${ }^{33}$. Dos de estos se encuentran también en la BNE: el ms. 3.794 (f. 222v) (ms. B) ${ }^{34}$ y el 19.387 (f. 72v), que fue de Gayangos (ms. C) $)^{35}$. El tercero es uno de los manuscritos poéticos que colec-

${ }^{32}$ Veremos cómo el ms. 19.387 de la BNE en la rúbrica manifiesta que se hizo «a san Roque en su fiesta», es decir, un 16 de agosto. Pero, sin saber el año, el dato nos sirve de poco.

${ }^{33}$ Otro manuscrito, el 3.879 (f. 261) de la BNE, no ofrece interés por ser una copia del siglo XIX del 3.795, con leves modernizaciones ortográficas. En efecto, un breve apunte tras la rúbrica confiesa que procede de un ms., f. 74v, que es el manuscrito de Góngora. Por eso mismo está claro que el nombre que figura como autor, «Miguel Saule», es uno de los pocos errores de copia.

${ }^{34}$ Es un cancionero con abundante poesía satírica del siglo XVII, al que luego se añadieron poesías del siglo XVIII.

${ }^{35}$ Es una copia más antigua que el anterior. Las poesías más tempranas, si atendemos a una fecha del principio, se copiaron en 1598. Luego se añadieron otras a lo largo del siglo XVII. 
cionó D. Ignacio de Toledo y Godoy y que se conocen hoy como Cancionero Antequerano ${ }^{36}$. En el Antequerano el poema es anónimo y como rúbrica solo lleva «De San Roque». No presenta muchas variantes, pero algunas son significativas: en lugar de enviar a su criado a la iglesia de Santiago, lo envía a «San Luis». Del v. 46 en adelante hay diferencias notables: el Antequerano añade dos versos más al final («que serán continuos mucho / y sus visitas me enfadan»), el «servidor de damas» ya no es el cura sino el emisario y los clérigos ahora no son «necios», sino «tiernos».

Los otros dos manuscritos de la BNE (B y C) llevan rúbricas parecidas entre sí: en ambas se declara que una dama es la autora del romance e, implícitamente, quien lleva el poema al religioso para participar en el certamen. En el ms. B leemos: «Vida de san Roque, escrita por una dama sevillana a una justa literaria y llevó el premio». Y en el ms. C: «Romance que hizo una dama a San Roque en su fiesta y llevó el premio». Aunque ambas copias presentan un texto con numerosas variantes de detalle entre sí, y con relación al que lo atribuye a Miguel Sánchez (ms. A), el cambio fundamental está en la rúbrica, que invita a pensar que es la dama quien lleva personalmente el poema al cura $\mathrm{y}$, «si es servidor de damas», insinúan que, al ir a buscar el galardón, tanto ella como el cura tendrían su respectivo «premio». Ambos manuscritos envían al emisario a la iglesia de San Luis, como el Antequerano, y no a Santiago. El cambio de lugar obedece seguramente a la necesidad de adaptar el texto a un contexto geográfico diferente, pues en Valladolid no había entonces una iglesia de San Luis. También el ms. A ofrece la variante separativa «mirad que hay clérigos necios», frente a los otros tres testimonios que prefieren «mirad que hay clérigos tiernos».

Sin entrar en más detalles ahora, se podría postular un stemma en el que el ms. A de la BNE constituyera una rama frente a un subarquetipo que denominaremos como «andaluz» y que englobara a los otros tres, pues el de Gayangos (ms. C) manifiesta un permanente seseo, el ms. B señala que la autora es una dama sevillana y el Antequerano es andaluz por razones obvias. Una variante interesante es la del v. 42: mientras los manuscritos B y C dicen «firmaré, poneos la espada», como quien se dirige a un escudero, el $A n$ tequerano prefiere «firmaré la vida santa» y el A «poned letra a las espaldas», sin marcar ningún rasgo masculino en el emisario que ha de llevar el poema. Otras variantes sugieren que los errores no son de copia, sino más bien consecuencia de la transmisión oral del romance.

Presenta abundantes casos de seseo. En el interior de la cubierta se afirma que lo compró Pascual de Gayangos en Londres en 1840.

${ }^{36}$ Este romance está en el segundo de los tres manuscritos poéticos de la colección, el denominado por Dámaso Alonso y Rafael Ferreres «Poesías de arte menor», por ser en él casi exclusivo el metro corto. D. Alonso y R. Ferreres publicaron solo 283 de los 701 poemas que contiene la colección manuscrita completa en Cancionero Antequerano, 1627-1628 (1950). El romance de san Roque aparece en las páginas 226-228 de esta edición. 
Con estos pocos datos, y habida cuenta de que los manuscritos no están datados, resulta difícil asegurar cuál es la versión más cercana al original. Quizá la clave esté en las rúbricas. Me inclino a pensar que el romance fue redactado por Miguel Sánchez tal vez estando la Corte en Valladolid, como indica la nota marginal, pues en el manuscrito que se lo atribuye hay muchas poesías vinculadas al paso de la Corte por la ciudad vallisoletana y, en concreto, muchos poemas burlescos dedicados al Pisuerga. Si hay base para justificar la autoría de Miguel Sánchez de este romance es porque el carácter jocoso del mismo y la concepción teatral de la burla contenida en el romance son muy cercanos al del romance de Gaiferos. Igualmente las palabras de Rojas Villandrando y de Cervantes sobre Miguel Sánchez parecen inspiradas en la originalidad de este poema. Por otro lado, la anonimia de tres de los manuscritos y el silencio de Sánchez desde que fue nombrado secretario de Enrique Enríquez, son indicios elocuentes de que la mano de Miguel Sánchez pudo estar escondida detrás de estos versos. Y en última instancia, la autoría femenina que declaran las rúbricas de B y C (y tal vez el Antequerano, que no dice nada al respecto) presenta la apariencia de ser elaboración posterior para visualizar mejor el significado erótico del poema: si el poema se pone en boca de una mujer y ella misma lo lleva en mano al cura, el poema adquiere una teatralidad tremendamente divertida. En cualquier caso, parece descartado que el texto haya sido escrito por una mujer. Creo que estas rúbricas que lo atribuyen a una dama solo pretenden situar al lector, u oyente, ante un autor femenino ficticio, para que así el affaire entre la autora del poema y el cura justifique mejor el resultado del certamen.

Por todo lo dicho - seseo, autoría de dama sevillana, Cancionero Antequerano-, cabe pensar que este romance de Miguel Sánchez sobre San Roque tuvo una considerable circulación manuscrita y oral por Castilla y por Andalucía. Viene, por tanto, a ratificar las fluidas relaciones entre poetas andaluces y castellanos que se materializan en las Flores de poetas ilustres de Espinosa (donde encontramos una canción de Miguel Sánchez) y en los intercambios que se prolongan de algún modo en los textos del Cancionero Antequerano, reunidos en la tercera década del seiscientos, donde se copia este poema burlesco de Sánchez sobre la vida de san Roque ${ }^{37}$.

\section{«En tres blancas está la poesía» [1615] y las fiestas de beatificación de Teresa de Jesús en Salamanca}

En la Relación de las fiestas de la ciudad de Salamanca en la beatificación de la Sancta Madre Teresa de Jesús... por Fernando Manrique de Luxán, obra publicada en Salamanca (1615: 92-93) se copia un soneto burlesco, atribuido a Miguel Sánchez, que dice así:

\footnotetext{
${ }^{37}$ Sin renunciar a nada de lo dicho, este romance merece un estudio monográfico detallado que coteje sus cuatro versiones y tenga en cuenta la datación de los cuatro manuscritos.
} 


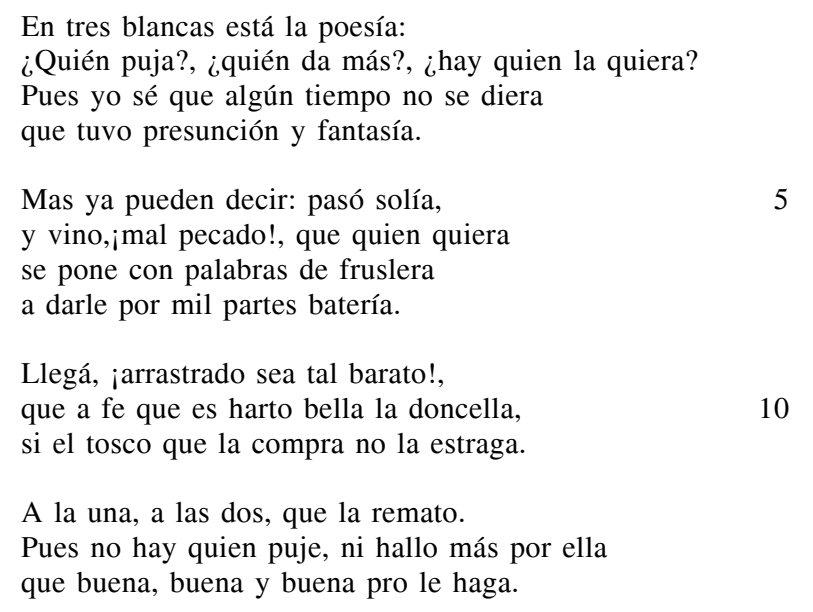

Teresa de Jesús había sido beatificada el 24 de abril de 1614 por Paulo V. La noticia llegó a Salamanca un mes después, el 26 de mayo, y tras grandes preparativos las fiestas mencionadas tuvieron lugar a principios de octubre de ese año. Stefano Arata señala que resulta por ahora imposible saber si dicho soneto es obra de nuestro dramaturgo o de un poeta homónimo. Hoy podemos asegurar, casi con total seguridad, que no lo compuso Miguel Sánchez Requejo, pues treinta y cinco años antes había sido ya impreso en El Arte poética en romance castellano, de Miguel Sánchez de Lima (Alcalá de Henares: Juan Íñiguez de Lequerica, 1580, f. 16), cuya licencia es de 1576. En esta obra el soneto aparece citado por uno de los personajes del diálogo inicial y en ningún caso se presenta como obra de Sánchez de Lima. Cuando Manrique de Luján atribuyó en 1615 el soneto a Miguel Sánchez pudo pesar el nombre del autor de El Arte poética en romance castellano, homónimo de nuestro poeta ${ }^{38}$.

En la Relación de las fiestas de la ciudad de Salamanca... el soneto atribuido a Miguel Sánchez se encuentra en un contexto festivo. Como era habitual en unas fiestas tan ruidosas, se leyeron y recitaron muchas poesías, la mayoría de baja calidad. Precisamente el soneto «En tres blancas está la poesía» abre la sección referida a la concesión de los premios de los certámenes poéticos, justo a continuación de dos composiciones en latín que igualmente

\footnotetext{
${ }^{38}$ Por otro lado, el soneto había sido atribuido a Francisco de Figueroa en el cancionero manuscrito 23/4/1 de la Biblioteca de don Bartolomé March, posterior según J.J. Labrador y R.A. Di Franco (1992) a la obra de Sánchez de Lima. Con todo, Christopher Maurer (1988: 106 y ss.) prefiere considerarlo como anónimo, si bien, emparentado con el soneto de Figueroa de similar temática y tono «¿Hay quien quiera comprar nueve doncellas...», motivo por el cual pudo atribuírselo el manuscrito mencionado. M. López Suárez (1989: 489) lo atribuye sin ninguna base a Miguel Sánchez de Lima.
} 
se burlan de la mala poesía. Es muy relevante el texto precedente, que dice así: «A todo lo qual miró el Ingenioso Castellano que hizo lo que se sigue [y en la línea siguiente] Soneto». El nombre «Miguel Sánchez» figura impreso al margen del primer verso, como se hace en otras páginas del libro para indicar el autor del poema. Debe destacarse que no es un soneto perteneciente a ninguno de los certámenes y por eso no obedece al tema propuesto ni se encuentra entre los sonetos de la justa poética: es un testimonio curioso de una colaboración especial.

No hay certeza de que nuestro poeta acudiera a estas celebraciones de Salamanca, pero residiendo en Plasencia como secretario de su obispo Enrique Enríquez, es muy probable que el obispo de Plasencia, acompañado de Miguel Sánchez, acudiera a estos festejos invitado por el de Salamanca don Luis Fernández de Córdoba, costumbre arraigada entre obispos de diócesis vecinas con ocasión de celebraciones tan especiales ${ }^{39}$.

En la Relación de las fiestas de 1615 el soneto se presenta como si hubiera sido compuesto para la ocasión: la concesión de los premios de los diversos certámenes. Miguel Sánchez Requejo no puede ser su autor, pues era demasiado joven en 1580 cuando Miguel Sánchez de Lima publicó «En tres blancas está la poesía», pero no es imposible que en las fiestas de beatificación de Santa Teresa de 1614 nuestro Miguel Sánchez recitara o pasara copia a Manrique de Luján de este soneto que denuesta la mala poesía, pues a fin de cuentas el tono de burla y el ritmo entrecortado no le eran ajenos a nuestro poeta. En definitiva, aunque descartamos la autoría del autor vallisoletano, seguimos sin saber quién era el Miguel Sánchez al que se refería Manrique de Luján en su edición de 1615.

\section{Otra POEsía ATRIBUible a Miguel SÁNCheZ}

\section{[«¿Quién yace aquí? Nadie ¿Cúya es la memoria?»]}

En el ms. 3.926 (f. 18) de la BNE se encuentra un soneto precedido de la siguiente rúbrica: «Soneto y epitafio a la muerte del Emperador Carlos Quinto, padre de nuestro rey D. Filipe Segundo. Por Sánchez». El manuscrito reúne poesía y teatro de finales del siglo XVI y principios del XVII. Un dato relevante es que el poema anterior es un epitafio, en este caso una octava, a

\footnotetext{
${ }^{39}$ Además, como agustino que era, Enrique Enríquez debía de tener en la ciudad muchos conocidos desde su época de Provincial de la Orden. Hay testimonios según los cuales las personas del lugar no habían conocido fiestas con un despliegue semejante. Acudieron muchas personas de otras ciudades y en estas celebraciones se hicieron sonar todas las campanas de la ciudad, hubo grandes dispendios en fuegos artificiales, se construyeron numerosos monumentos de arquitectura efímera con poemas alegóricos, las justas poéticas se desplegaron en once certámenes o modalidades, etc.
} 
la muerte del príncipe don Carlos, el hijo de Felipe II que había fallecido el 24 de julio de 1568. La rúbrica termina con un escueto «Por Damasio», nombre que nos remite a Damasio de Frías, poeta que vivió en Valladolid en la segunda mitad del siglo XVI y de edad algo mayor que Miguel Sánchez. Si al copista le basta el nombre de «Damasio» para referirse a Damasio de Frías, hemos de admitir que «Sánchez» pudo ser su paisano Miguel Sánchez Requejo. Por mucho que nos parezca forzada la identificación, si un nombre tan común como Miguel Sánchez bastó en la época para referirse a nuestro autor, su apellido también debió de parecer suficiente a este copista. Si leemos sus versos, apreciamos que es un soneto primerizo, de alguien que se esfuerza en doblegar el léxico y la sintaxis para someterlos a una forma estrófica tan cerrada. El propio tema es tópico, pues el emperador había muerto ya hacía mucho tiempo, quizá antes de que naciera el poeta. Por sus tanteos de poeta primerizo y su ubicación en el manuscrito, no pasa de ser un ejercicio poético siguiendo la estela del poema compuesto por Damasio de Frías. Hemos de decir, además, que alguna nota ya apunta al estilo que luego veremos con frecuencia en la poesía de Miguel Sánchez, como esas dos interrogaciones del primer verso separadas por la respuesta «Nadie», o ese quinto verso, tan coloquial y en este caso tan fallido: «¿Es Alejandro? No, que ese es escoria». En ambos ejemplos comprobamos ya la preferencia por las preguntas breves y la construcción de un verso con dos o más oraciones. Si este poema es de nuestro Miguel Sánchez, debe de ser la obra más temprana que conservamos, un mero ejercicio literario en un género tan clásico como el epitafio.

\section{A MODO DE CONCLUSIÓN}

Los poemas de Miguel Sánchez aquí reunidos nos muestran con suficiente variedad su versatilidad como poeta. Los dos más conocidos, la canción lírica a Cristo crucificado y el romance burlesco de don Gaiferos, ofrecían una imagen demasiado esquemática y más bien desconcertante. Su maestría como poeta religioso y su destreza en el arte de la burla quedaban bien ejemplificadas, pero había que dar algunos pasos más. Los sonetos laudatorios revelan soltura y dominio en el manejo de esta estrofa. Estos poemas encomiásti$\cos$ y de circunstancias se mueven entre la seriedad del dedicado al músico Montanos y el más jocoso del Orlando traído a las orillas del Pisuerga. Su conservación en los correspondientes libros de los autores agasajados atestigua una forma típica de pervivencia, imposible en otros poemas de circunstancias. El romance sobre la vida de san Roque nos confirma hasta dónde podía llegar la capacidad de invención y provocación que tanto sorprendió a Rojas Villandrando; el planteamiento descabellado del poema debió de hacer las delicias de muchos lectores y oyentes. Quizá el carácter de estos versos, y de otros similares que seguramente se han perdido definitivamente, nos dan la clave 
de su silencio posterior. Si en 1603 Villandrando le reconoce a Miguel Sánchez una originalidad fuera de lo común (próxima seguramente a las desplegadas en el Valladolid de la Corte por los grandes genios que hasta allí se desplazaron) y a la vez aspiraba a ser secretario de un obispo de la más rancia aristocracia, quizá tuvo que pagar el precio de renunciar a la poesía, al menos en su faceta pública. El secretario del obispo de Osma desapareció del panorama literario en la primera década del siglo, haciéndonos ver con su silencio que el ejercicio de la poesía, al menos en su vertiente más festiva, no era compatible en aquella época con la seguridad económica de ciertas ocupaciones eclesiásticas.

\title{
EDICIÓN DE LAS POESÍAS DE MIGUEL SÁNCHEZ ${ }^{40}$
}

\section{1. «A Pedro Escobar Cabeza de Vaca» [1587]}

\author{
De nuevo tiendes, Escobar, las velas \\ al célebre viaje que acabaste; \\ en él hasta hoy el cuerpo desvelaste, \\ y ya cuerpo y espíritu desvelas. \\ Tanto en servir tu rey y patria velas ${ }^{41}$, \\ que, por la santa tierra que pisaste, \\ si con devotos pies peregrinaste, \\ agora con heroica pluma vuelas. \\ Tú mismo a tu saber materia diste, \\ $\mathrm{y}$ en versos mides lo que ya has medido \\ 10 \\ con pasos de valor tan sin medida, \\ que, cuando el mundo que con pies mediste \\ se muestre en alabarte comedido, \\ no habrá alabanza que contigo mida $^{42}$.
}

\footnotetext{
${ }^{40}$ Como es ya muy habitual en la edición de nuestros clásicos del siglo XVII, modernizo la ortografía, acentuación y puntuación para una más fácil lectura manteniendo fonemas distintos y las peculiaridades morfológicas del texto («miraldo», «consultallo», «decilde»). Salvo el romance de Gaiferos y el de San Roque, todas las demás composiciones se han conservado en un solo testimonio que ya ha sido identificado en el estudio preliminar. La fuente para la edición de ambos romances se especifica en la primera nota de la edición de cada uno.

${ }^{41}$ Como se dijo, Escobar había sido militar. Obsérvese el juego de palabras en torno a «velas» usado como sustantivo y como verbo.

${ }^{42}$ Nótese el artificio retórico que supone jugar con términos de la familia léxica de «medir» en los cinco versos finales.
} 


\section{2. «Al músico Francisco de Montanos» [1592]}

Cualquiera pecho en voz subida o grave bendice de su Dios la mano santa, que le formó, por cuya merced tanta, solo le pide amor, con que le alabe.

El ángel a quien parte mayor cabe

de aqueste oficio, su alabanza canta, a cuya imitación allá levanta su voz el hombre, como puede o sabe.

Lo que es al ángel propio, con el arte tuyo, sabio Montano ${ }^{43}$, el hombre alcanza $\mathrm{y}$ en esto el ángel ya se iguala al hombre.

Tome Dios a su cargo el alabarte, pues a su cargo tomas su alabanza y haga inmortal su eternidad tu nombre.

\section{3. [«Oíd, señor don Gaiferos» $]^{44}[1593]$}

Oíd ${ }^{45}$, señor don Gaiferos, lo que como amigo os hablo, que los dones más de estima suelen ser consejos sanos. Dejad un poco las tablas, escuchadme lo que entrambos - yo aconsejar, vos hazer-, debemos a hijosdalgo ${ }^{46}$. Melisendra está en Sansueña ${ }^{47}$,

${ }^{43} \mathrm{La}$ forma «Montano», sin la -s final permite la sinalefa y la medida correcta del verso.

${ }^{44}$ Tomo como base el Romancero general (Madrid: Luis Sánchez, 1600), reproducido en facsímil por Archer M. Huntington del original de su biblioteca (1904: f. 44) y ahora disponible en línea: http://books.google.es/books?id=tCNGAQAAIAAJ\&printsec=frontcover\&hl=es\&source= gbs_ge_summary_r\&cad=0\#v=onepage \&q\&f=false [ref. de 25/02/2015].

${ }^{45}$ El romance combina la segunda persona, que amonesta a Gaiferos, con la tercera narrativa.

${ }^{46}$ La sintaxis del pasaje es bien original: el sujeto de «debemos» (nosotros) se desdobla en un «yo aconsejar» y un «vos hazer», construcción que resulta muy teatral.

${ }^{47}$ El nombre de Sansueña procede de la adaptación al español del topónimo francés Sansoigne o Sansuenha (Sajonia) donde se refería a una ciudad mora, sin que los romances la identifiquen con Zaragoza (Menéndez Pidal, 1953, I: 255-256). Ya en el siglo XVI se identificó con Zaragoza, significado que adopta en Cervantes (Quijote, II, 26). Cristóbal Cuevas en su edición de las Poesías completas de Fray Luis de León, al anotar la Profecía del Tajo (2001: 113) se plantea también si se refiere a Pamplona o Talamanca (provincia de Madrid), como pensaba Iriarte. Victor Millet ofrece una amplia relación de menciones 
vos en París descuidado;

vos ausente, ella mujer,

harto os he dicho, miraldo ${ }^{48}$.

Aseguraos su nobleza,

mas no os asegura tanto

que vence un presente gusto

mis nobles ante pasados.

De Carlos el Rey es hija,

mas es mujer y ha más años

la mudanza en las mujeres

que no la nobleza en Carlos $^{49}$.

Si enferma la voluntad,

morirán respetos altos,

que no basta sangre buena,

si el corazón no está sano.

Galanes moros la sirven

$\mathrm{y}$, aunque moros, recelaldos,

que sin duda querrá un moro

la que olvidare un cristiano.

Diferentes son las leyes,

mas no hay ley en pecho humano

cuando llega a ser el alma

idólatra de un cuidado.

Las mujeres son espejo,

que mirándole es retrato,

mas descuidaos: si otro llega,

hará con él otro tanto ${ }^{50}$.

$\mathrm{Su}$ confuso entendimiento

es codicioso letrado,

que hace leyes siempre al gusto

del que llega a consultallo;

su memoria es mar revuelto

que luego que pasa el barco,

si le buscáis el camino,

no hallaréis senda ni rastro,

su voluntad mesonera

que aloja a los más extraños

y olvida al que del umbral

de sacar acaba su paso ${ }^{51}$.

No quiero deciros más,

literarias de Sansueña y sus variantes, y llega a la conclusión de que en los romances, una vez olvidado que el topónimo procede de Sajonia, se refiere siempre a una tierra de gentes paganas (1998: 172-174).

${ }^{48}$ Este es el verso que menciona Cervantes en el pasaje de Maese Pedro y que llegó a hacerse proverbial.

${ }^{49}$ Para Rojas Villandrando los versos sentenciosos caracterizaban la poesía de Miguel Sánchez. Obsérvese al respecto los vv. 19 y 20, y luego los vv. 27 y 28.

${ }^{50}$ Desarrolla aquí el lugar común de que la mujer es reflejo de quien la mira. Por eso, si alguien la descuida y otro la mira, reflejará a ese nuevo hombre.

${ }^{51}$ Alusión erótica muy atrevida. Los versos 33-48 reúnen motivos antifeministas. 
con esto de mi amor salgo,

mas ha movido ${ }^{52}$ mi lengua

vuestro amor y mis agravios.

\section{4. «A Pero López Henríquez de Calatayud» [1594]}

Muestra, Valladolid, nuevo contento;

madre de reyes ${ }^{53}$, muéstrate gozosa,

pues, como en hijos siempre venturosa,

hoy halla Orlando en ti su nacimiento.

Dátele otro hijo ${ }^{54}$, cuyo entendimiento,

padre de tu república famosa,

la rige con industria cuidadosa,

y hoy pone en este blasón aqueste aumento.

Madre halla en ti cualquier nación extraña,

y halla a aqueste capitán famoso,

que no habrá gloria donde parte no halles ${ }^{55}$.

Tú haces y deshaces, libre España,

si en Francia vive amante y furioso,

nace en Pisuerga y muere en Roncesvalles ${ }^{56}$.

\section{5. «Romance a san Roque» $[\text { h. 1601-1605] }]^{57}$}

[Romance con que se cumple con un certamen que pedía se dijese la vida de san Roque en breves palabras. Miguel Sánchez]

\footnotetext{
${ }^{52} \mathrm{El}$ texto dice «a menudo». La lectura correcta, «ha movido», figura en la fe de erratas que va después de la «Tassa» en el propio Romancero firmada por Juan Vázquez del Mármol. Eugenio de Ochoa en lugar de «a menudo» pone «adviérteos».

${ }^{53}$ En efecto, el rey Felipe II había nacido en Valladolid el 21 de mayo de 1527. No podía entonces Miguel Sánchez adivinar que años más tarde participaría él mismo en el bautismo del que con el tiempo sería Felipe IV (nacido en Valladolid el 8 de abril de 1605), acompañando al obispo de Osma, Enrique Enríquez, de quien ya era secretario.

${ }^{54} \mathrm{La}$ forma verbal «Da» no está en imperativo, como puede parecer a primera vista. La lectura correcta es «Te lo da otro hijo» (de Valladolid), es decir, López Henríquez. No debe desconcertarnos el leísmo, muy habitual en la época.

${ }^{55}$ El terceto destaca la capacidad que tiene Valladolid de acoger a cualquier personaje legendario, a la vez que la ensalza como ciudad gloriosa.

${ }^{56}$ En el último terceto el elogio se extiende a España, capaz de españolizar a este héroe de origen francés.

${ }^{57}$ Sigo el texto del ms. 3.795 de la BNE (f. 74v). Cabría relacionar un certamen poético sobre san Roque, protector ante la peste, con la epidemia que asoló Valladolid y toda Castilla en 1599, pero la convocatoria de un certamen literario como este, con motivo de su fiesta, no requería de especiales justificaciones.
} 
¡Jesús!, ¡qué tarde despierto!

¡Hola!, ¿no hay criada? ${ }^{58}$

Pérez, dadme ese manteo,

ligas, zapatillas, calzas,

ese cartón, esas cintas.

La pretinilla ${ }^{59}$, dejalda ${ }^{60}$

y dadme por ella presto

aquella adobada ${ }^{61}$ de ámbar.

Dadme la ropa, la azul,

pero, no: dadme la blanca,

que aún ahora el raso ${ }^{62}$ pesa

y es el tafetán ${ }^{63}$ más gala.

Sacad la toca con listas,

mostrá ${ }^{64}$ el espejo: ¡qué cara

para negar una deuda!

Sacadme de allí dos pasas.

Hoy no me admitáis visitas.

¿Tenéis pastilla? Dos brasas

mostrad para el sahumerio.

Abrid aquella ventana.

¿Qué torpe sois! No la reja, esa celosía, la alta.

Sacá aquel libro. No aquél,

ni aquel, ni aquella Diana,

ni el pícaro, ni Amadís ${ }^{65}$,

ni ese de las cintas pardas.

El Flos sanctorum, ese es.

Buscá a Roque en la tabla

¿No le halláis? Id a los santos

extravagantes ${ }^{66}$. Doy gracias

\footnotetext{
${ }^{58}$ Nótese que el verso es hipométrico.

${ }^{59}$ La pretina o pretinilla era el cinturón de cuero.

${ }^{60} \mathrm{La}$ metátesis en el imperativo, «dejalda» en lugar de «dejadla», es muy frecuente en el Siglo de Oro.

${ }^{61}$ Arreglada, teñida.

${ }^{62}$ Tela de seda de más cuerpo que el tafetán.

${ }^{63}$ Tela delgada de seda.

${ }^{64} \mathrm{La}$ forma del imperativo «mostrá» alterna con «mostrad» en la época, como vemos en el v. 19. Con el mismo valor imperativo aparece «sacá» en el v. 23 , «buscá» en el v. 28 y «llamá» en el v. 32.

${ }^{65}$ La mención irónica de estos libros, tan exitosos en el siglo XVI, no deja de ser un testimonio de las lecturas más comunes, junto con las vidas de santos. El pícaro mencionado podía aludir al Lazarillo, pero también podía ser el Guzmán de Alfarache, cuya primera parte se publicó en Madrid en 1599 y la segunda en Lisboa en 1604.

${ }^{66}$ Eran llamados comúnmente «santos extravagantes» aquellos que no estaban incluidos por la Iglesia en las oraciones del Breviario. En 1604 aparece publicada la obra del P. Pedro de Ribadeneira, Libro de vidas de santos, que comúnmente llaman extravagantes, porque comúnmente la Yglesia no reza dellos en el Breviario Romano (1604). En la biografía de San Roque (1604: 168-170) se ofrecen todos esos datos (aunque no se menciona Narbona sino Montpellier, en la provincia del Languedoc, como lugar de nacimiento) y otros muchos
} 
a Dios que le habéis hallado

Llamá al escudero, ¡basta!

Tomad papel, tinta y pluma.

Escribid: «Nacido en Françia, en Narbona, fue a Roma

y libró de peste a Italia.

Su renta gasta con pobres, fue preso en su propia patria, calló cinco años, murió y goza de Dios su alma.

¿Es más de esto? No, mostrad:

Firmaré. Poneos la espada, id a Santiago ${ }^{67}$, allá dentro tiene casa el cura. ¡Erradla! ${ }^{68}$ Dadle este papel. Decidle que si es servidor de damas, que le defienda y que cuándo que vais ${ }^{69}$ por el premio manda. Mirad que hay clérigos necios, no le digáis nuestra casa.

\title{
6. «Canción a Cristo crucificado» $[1605]^{70}$
}

\author{
Inocente Cordero, \\ en tu sangre bañado,
}

\begin{abstract}
como su muerte en 1327; se destaca en especial la devoción que creció en torno a él por ser considerado protector frente a la peste. Cabría utilizar la fecha de publicación del libro, 1604, para datar este romance, pero a nadie se le escapará que un licenciado como Miguel Sánchez podría conocer la biografía de este santo «extravagante» por otra fuente, antes de que fuera publicado el libro del jesuita Ribadeneira. Desde el Flos sanctorum publicado por el impresor Jorge Cocci (Zaragoza, 1516), diversas ediciones aparecieron en el siglo XVI. En 1577, por ejemplo, Alonso de Villegas había publicado un Flos sanctorum (Toledo, Diego de Ayala) ajustado a la doctrina de Trento donde figuraban «las vidas de los santos propios de España junto a otros extravagantes». Esa obra se extendió hasta los seis tomos y se reeditó varias veces en los siglos XVII y XVIII.

${ }^{67}$ La iglesia de Santiago, en la calle de su mismo nombre, está situada entre la Plaza Mayor y la actual Plaza de Zorrilla, en uno de los lugares más céntricos y tradicionales de Valladolid.

${ }^{68}$ No he encontrado en los diccionarios del siglo de oro el significado de esta expresión, seguramente coloquial, que aparece idéntica en los cuatro manuscritos. Quizá sea equivalente a la actual «iPerdeos!», que se suele decir con ironía.

${ }^{69} \mathrm{El}$ indicativo «vais» debe interpretarse como nuestro subjuntivo «vayáis». El sentido del pasaje sería: «decidle que lo defienda y que cuándo manda que vayáis por el premio».

${ }^{70}$ En la primera edición de la Primera parte de Flores de poetas ilustres (Valladolid, 1605) los editores modernos I. Pepe Sarno y J.M. Reyes Cano distinguen hasta tres estadios, con cambios importantes entre sí (Espinosa, 2006). Como ellos, tomo el texto del ejemplar R/31598 de la BNE. Al nombre del autor le siguen inmediatamente los versos de la canción. El título Canción a Cristo crucificado es el que ha establecido después la tradición a partir del siglo XVIII.
\end{abstract}


con que del mundo los pecados quitas,

del robusto madero por los brazos colgado,

abiertos, que abrazarte a mí me incitas; ya que, humilde, marchitas

el color y hermosura

de ese rostro divino,

a la muerte vecino,

antes que el alma soberana y pura

parta para salvarme,

vuelve los mansos ojos a mirarme ${ }^{71}$.

Ya que el amor inmenso,

con último regalo,

rompe de tu grandeza las cortinas,

y con dolor intenso,

arrimado a ese palo,

la cabeza clavada con espinas

hacia la Madre inclinas;

ya que la voz despides,

bien de entrañas reales,

y las culpas y males

a la grandeza de tu Padre

pides que sean perdonados ${ }^{72}$,

acuérdate, Señor, de mis pecados ${ }^{73}$.

Aqui ${ }^{74}$ donde das muestras

de manirroto ${ }^{75}$ y largo,

con las manos abiertas con los clavos,

y que las culpas nuestras

has tomado a tu cargo;

aquí, donde redimes los esclavos,

donde por todos cabos

misericordias brotas,

y el generoso pecho

no queda satisfecho

hasta que el cuerpo de la sangre agotas;

aquí, Redentor, quiero

llegar a tu juïcio yo el primero.

Aquí quiero que mires

${ }^{71}$ Por el hipérbaton tan acusado, el verbo principal («vuelve») se sitúa en el último verso de esta primera estancia y concentra en él toda la fuerza de su contenido. El poeta nos sitúa justo antes de que Cristo entregue su alma a Dios.

${ }^{72}$ Es la primera de las siete palabras: «Padre, perdónales porque no saben lo que hacen» (Lucas 23, 34).

${ }^{73}$ También con un verbo en imperativo («acuérdate») termina esta segunda estancia. Las oraciones temporales iniciadas por «ya que» (vv. 7, 14 y 21), situadas estratégicamente, imprimen un ritmo vehemente a la composición.

${ }^{74}$ Obsérvese que mediante la repetición del adverbio «aquí» (vv. 27, 32, 38, 40) en este verso se inicia una nueva anáfora que organiza los contenidos e imprime ritmo al texto.

${ }^{75}$ El doble sentido con el que aquí se juega de «manirroto» («con las manos taladradas por los clavos» $\mathrm{y}$ «pródigo en exceso») no parece afortunada. 
a un pecador metido

en la ciega prisión de sus errores;

que no temo te aíres ${ }^{76}$

en mirarte ofendido,

pues abogando estás por pecadores,

y las culpas mayores

son las que más declaran

tu noble pecho santo

de que te precias tanto;

pues cuando las más graves se reparan,

en más tu sangre empleas

y más con tu clemencia te recreas.

Por más que el peso grave

de mi culpa presente

cargue sobre mi flaco y corvo cuello,

que tu yugo süave

sacude inobediente,

quedando en dura sujeción por ello;

y aunque la tierra huello ${ }^{77}$

con pasos tan cansados,

alcanzarte confío;

que, pues por el bien mío

tienes los soberanos pies clavados

en un madero firme,

seguro voy que no podrás huirme ${ }^{78}$.

Seguro voy, Dios mío,

que, pues yo lo deseo,

he de llegar de tu clemencia al puerto;

que tu corazón frío,

a quien ya claro veo ${ }^{79}$

por las ventanas de ese cuerpo abierto ${ }^{80}$,

está tan descubierto,

que un ladrón maniatado,

que lo ha contigo a solas,

con dos palabras solas

te lo tiene, piadoso Dios, robado ${ }^{81}$;

y si aguardamos, luego,

porque te acierta, das la vida a un $\operatorname{ciego}^{82}$.

A un buen tiempo he llegado,

pues es cuando tus bienes

repartes en el Nuevo Testamento;

\footnotetext{
${ }^{76}$ Del verbo «airar», derivado de «ira». Salvo en participio, hoy está en desuso.

${ }^{77}$ Del verbo «hollar», hoy poco utilizado, salvo en participio.

${ }^{78} \mathrm{La}$ expresión actual equivalente sería «seguro estoy de que no podrás rehuirme».

79 «a quien» se refiere «al corazón», aquí personificado.

${ }^{80}$ Las ventanas son metafóricamente las grandes heridas que dejan ver el corazón.

${ }^{81}$ Se refiere al pasaje de San Mateo sobre el Buen Ladrón, llamado Dimas en los Evangelios apócrifos.

${ }^{82}$ Referencia al milagro en que Jesús devuelve la vista al ciego de Jericó.
} 
si a todos has mandado

cuantos presentes tienes,

también yo ante tus ojos me presento;

aquí, en sólo un momento,

a la Madre hijo mandas,

al discípulo Madre ${ }^{83}$,

el espíritu al Padre ${ }^{84}$,

gloria al ladrón ${ }^{85}$. Pues entre tantas mandas,

¿ser mi desgracia puede

tanta que sólo yo vacío quede?

Mírame, que soy hijo,

aunque mi inobediencia

justamente podrá desheredarme;

pues tu palabra dijo

que hallaría clemencia

siempre que a ti viniese a presentarme.

Aquí abrazarme

a los pies de esta cama,

donde morir te veo;

que si, como deseo,

oyes la voz piadosa que te llama,

en tu clemencia espero

que, siendo hijo, quedaré heredero.

Por testimonio pido

a cuantos te están viendo

cómo a este punto bajas la cabeza:

señal que has concedido

lo que te estoy pidiendo,

como siempre esperé de tu grandeza.

$\mathrm{Y}$ inefable largueza,

caridad verdadera;

porque aunque, como es cierto,

que, el testador no muerto,

no tiene el testamento fuerza entera,

tan magnánimo eres

que, por que todo se confirme, mueres.

Canción, de aquí no paso ${ }^{86}$;

las lágrimas sucedan

${ }^{83}$ Recuerdo del momento de la Pasión en que Jesús, al ver su Madre y junto a ella el discípulo a quien amaba, le dice: «iMujer, ahí tienes a tu hijo!» (Juan 19, 26). Y luego le dice al discípulo: «iAhí tienes a tu madre!» (Juan 19, 27). Es la tercera palabra.

${ }^{84}$ Jesús en la cruz, justo antes de morir, se dirige al Padre con estas palabras: «En tus manos encomiendo mi espíritu» (Lucas 23, 46). Es la séptima palabra.

${ }^{85}$ Se refiere el poeta al momento en que Jesús promete al Buen Ladrón: «Hoy estarás conmigo en el Paraíso» (Lucas 23, 43). Es la segunda palabra.

${ }^{86}$ Era habitual que la canción renacentista se escribiera en estancias (en este poema, de trece versos cada una) y que se rematara con un «envío» más breve. El recurso de interpelar a la propia canción en la estrofa final mediante un vocativo ya aparece en las cuatro 
en vez de las palabras que me quedan,

cual lo requiere el lastimoso caso;

no canto más agora,

pues que la tierra, mar y cielo llora.

\section{OTRA POESÍA ATRIBUIBLE A MIGUEL SÁNCHEZ}

\section{7. «Epitafio a la muerte del Emperador Carlos V»}

[Soneto y epitafio a la muerte del Emperador Carlos Quinto, padre de nuestro rey D. Filipe Segundo. Por Sánchez]

¿Quién yace aquí? Nadie. ¿Cúya es la memoria?87

De un ánimo de Marte esclarecido,

de un vencedor que nunca fue vencido,

que donde Febo alumbra tiene gloria.

¿Es Alejandro? No, que ese es escoria

con nuestro Carlos Quinto conferido ${ }^{88}$, que en ése ${ }^{89}$ harto fue no ser vencido, mas Carlos ha vencido la Victoria.

Aquese fue en el siglo sin segundo, burló en el mejor tiempo a la fortuna después de a grandes hechos poner cima.

No basta a sus loores pluma alguna, pues no hay cosa mejor en este mundo que un ánimo que mucho en poco estima.

\section{BIBLIOGRAFÍA}

Aizpurua, Pedro (1983). «El vallisoletano Francisco de Montanos (s. XVI), teórico musical y polifonista», Revista Española de Musicología. 6, 1-2, pp. 109-120.

Alonso, Dámaso y Rafael Ferreres (ed.) (1950). Cancionero Antequerano, 1627-1628. Madrid: CSIC.

Alonso Cortés, Narciso (1906). Noticias de una corte literaria. Valladolid: Imprenta La Nueva Pincia.

primeras canciones de Garcilaso. Estos versos metaliterarios, que conllevan un cambio de «destinatario», introducen un elegante y reflexivo distanciamiento. El final de la canción de Miguel Sánchez, muy logrado en sus dos versos finales, debió de sorprender a sus contemporáneos por su equilibrio y musicalidad.

${ }^{87}$ Nótese que el verso es hipermétrico, sobra una sílaba

88 «conferido»: 'comparado'.

${ }^{89} \mathrm{Se}$ refiere a Alejandro, que aunque no fue vencido, Carlos le supera por haber vencido a la Victoria. 
Alonso Cortés, Narciso (1921). «Miguel Sánchez "El Divino"», en Miscelánea vallisoletana (Tercera serie). Valladolid: Tipografía Cuesta, pp. 123-131.

Alonso Cortés, Narciso (1926). «El traductor de Ludovico Dolce», en Miscelánea vallisoletana (Cuarta serie). Valladolid: Imprenta del Colegio de Santiago, pp. 151-166.

Alonso Cortés, Narciso (1944). «Los poetas vallisoletanos celebrados por Lope en el Laurel de Apolo», en Miscelánea vallisoletana (Séptima serie). Valladolid: Imprenta Castellana, pp. 5-58.

Amselem-Szende, Line (2003). «Encarnación de Lope de Vega en los Soliloquios de un alma a Dios», Criticón. 87-88-89, pp. 19-34.

Arata, Stefano (1985). «Un’opera sconosciuta di Miguel Sánchez «El Divino»: La tragicomedia de la desgracia venturosa», Cultura Neolatina. 45, pp. 125-140.

Arata, Stefano (1989). Miguel Sánchez il «Divino» e la nascita della comedia nueva. Salamanca: Acta Salmanticensia.

Arata, Stefano (1996). «Teatro y coleccionismo teatral a finales del siglo XVI. (El conde de Gondomar y Lope de Vega)», Anuario de Lope de Vega. 2, pp. 7-23.

Arellano, Ignacio (1995). Historia del teatro español del siglo XVII. Madrid: Cátedra.

Arnaud, Emile (1981). «Alonso Jerónimo de Salas Barbadillo: Epigramas», Criticón. 13, pp. 30-86.

Asensio, Eugenio (1965). Itinerario del entremés. Madrid: Gredos.

Barrera, Cayetano A. de la (1860). Catálogo bibliográfico y biográfico del teatro antiguo español. Madrid: [s. n.].

Bennassar, Bartolomé (1989). Valladolid en el Siglo de Oro. Una ciudad de Castilla y su entorno agrario en el siglo XVI. Valladolid: Ámbito-Ayuntamiento de Valladolid.

Blecua, José Manuel (1984). «La transmisión de la obra poética de Fray Luis de León», en P. Jauralde, D. Noguera y A. Rey (ed.), en La edición de textos. Actas del I Congreso de la Asociación Internacional del Siglo de Oro (AISO). London: Tamesis Books, pp. 13-30.

Bruerton, Courtney (1944). «The Chronology of the comedias of Guillén de Castro», Hispanic Review. 12, pp. 89-151.

Castro, Guillén de (1925). Obras de Guillén de Castro y Bellvis, II. E. Juliá Martínez (ed.). Madrid: Real Academia Española-Imprenta de la Revista de Archivos, Bibliotecas y Museos.

Cervantes, Miguel de (1995). Viaje del Parnaso II. Obra completa III. Florencio Sevilla Arroyo y Antonio Rey Hazas (ed.). Alcalá de Henares: Centro de Estudios Cervantinos.

Darby, Delphine Fitz (1938). Francisco Ribalta and his school. Cambridge: Harvard University Press.

Devoto, Daniel (1989). «Notomías», Bulletin Hispanique. 91, pp. 169-229.

Escobar Cabeza de Vaca, Pedro (1587). Luzero de la Tierra Santa y grandezas de Egypto y monte Sinay, agora nuevamente vistas y escriptas. Valladolid: Bernardino de Santo Domingo.

Espinosa, Pedro (2006). Primera parte de flores de poetas ilustres. Inoria Pepe Sarno y José María Reyes Cano (ed.). Madrid: Cátedra. Colección Letras Hispánicas 588; Primera edición Valladolid: Luis Sánchez, 1605.

Figueroa, Francisco de (1989). Poesía. Mercedes López Suárez (ed.). Madrid: Cátedra. Colección Letras Hispánicas 301.

Franchi, Fabio (1636). Essequie poetiche overo delle muse italiane in morte del Signore Lope de Vega. Venezia: Gherardo Imberti.

Góngora, Luis de (1982). Romances. Antonio Carreño (ed.). Madrid: Cátedra.

Herrera Maldonado, Francisco (1620). Sannazaro español. Los tres libros del parto de la Virgen Nuestra Señora, traducción castellana de versos heroycolatinos. Madrid: Fernando Correa Montenegro.

Huerta Calvo, Javier (dir.) (2003). Historia del teatro español, I. Madrid: Gredos. 
Huntington, Archer M. (ed.) (1904). Romancero general [en línea], en http://books.google.es/ books?id=tCNGAQAAIAAJ\&printsec $=$ frontcover\&hl $=$ es\&source $=$ gbs_ge_summary_r\&cad $=0 \# v=$ onepage\&q\&f=false [ref. de 25/02/2015]. Primera edición Madrid: Luis Sánchez, 1600.

Jiménez Patón, Bartolomé (1604). Eloquencia española en arte. Toledo: Tomás de Guzmán.

Josse, Agustín Luis (ed.) (1802). El Tesoro Español o Biblioteca Portátil Española. Londres: [s. n.].

Labrador Herraiz, José J. y Ralph A. Di Franco (1992). «El manuscrito 23/4/1 de la Biblioteca de don Bartolomé March», Bulletin Hispanique. 94-1, pp. 293-325.

Lama, Víctor de (2011). «"Engañar con la verdad”, Arte nuevo, v. 319», Revista de Filología Española. 91, 1, pp. 113-128.

Lama, Víctor de (2013). «Miguel Sánchez en el Arte nuevo y sus avatares editoriales», en Teatro español de los Siglos de Oro: dramaturgos, textos, escenarios, fiestas. Madrid: Visor, pp. 269-285.

Lama, Víctor de (en prensa). «El vallisoletano Pedro Escobar Cabeza de Vaca en su Luzero de la Tierra Sancta», Castilla. Estudios de Literatura.

López de Sedano, Juan José (ed.) (1771). Parnaso español (Colección de poesías escogidas de los más célebres poetas castellanos), V. Madrid: Ibarra.

Luis de León, Fray (2001). Poesías completas. Cristóbal Cuevas (ed.). Madrid: Castalia.

Manrique de Luján, Fernando (1615). Relación de las fiestas de la ciudad de Salamanca en la beatificación de la Sancta Madre Teresa de Jesús. Salamanca: Diego Cussio.

Maurer, Christopher (1988). Obra y vida de Francisco de Figueroa. Madrid: Istmo.

Menéndez Pidal, Ramón (1953). Romancero hispánico. Madrid: Espasa Calpe, 2 vols.

Mérimée, Ernest (1908). Précis d'histoire de la Littérature Espagnole. Paris: Garnier Frères.

Merino, Antolín (ed.) (1816). Obras del M. Fr. Luis de León. Madrid: Ibarra.

Millet, Victor (1998). Épica germánica y tradiciones épicas hispánicas: Waltharius y Gaiferos. La leyenda de Walther de Aquitania y su relación con el romance de Gaiferos. Madrid: Gredos.

Montanos, Francisco de (1592). Arte de música theórica y práctica. Valladolid: Diego Fernández de Córdova y Oviedo.

Ochoa, Eugenio de (1838). Tesoro de los romanceros y cancioneros históricos, caballerescos, moriscos y otros. París: [s. n.].

Olivar, Alexandre (1977). Catàleg dels manuscrits de la Biblioteca del Monestir de Montserrat. Montserrat: Publicacions de l'Abadía de Montserrat.

Rennert, Hugo (ed.) (1896). La isla bárbara y La guarda cuidadosa de Miguel Sánchez. Boston, Publications of the University of Pennsylvania, 1896.

Ribadeneira, Pedro de (1604). Libro de vidas de santos, que comúnmente llaman extravagantes, porque comúnmente la Yglesia no reza dellos en el Breviario Romano. Madrid: Luis Sánchez.

Rojas Villandrando, Agustín de (1977). El viaje entretenido. Jacques Joset (ed.). Madrid: Espasa Calpe, 2 vols.

Suárez de Figueroa, Cristóbal (1615). Plaza universal de todas ciencias y artes. Madrid: Luis Sánchez.

Vega, Félix Lope de (1621). La Filomena con otras diversas rimas, prosas y versos. Madrid: Viuda de Alonso Martín.

Vega, Félix Lope de (1630). Laurel de Apolo. Madrid: Juan González.

Vega, Félix Lope de (1975). La Arcadia, E. Morby (ed.). Madrid: Castalia.

Williamsen, Vern G. (1980). «El teatro de Miguel Sánchez, "El Divino"», en Actas del sexto congreso internacional de hispanistas. Toronto: University of Toronto, pp. 803-807.

Fecha de recepción: 4 de febrero de 2013.

Fecha de aceptación: 5 de julio de 2013. 